\title{
Underutilization of prophylactic rectal indomethacin and pancreatic duct stent for prevention of post-ERCP Pancreatitis
}

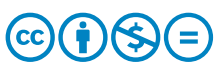

\author{
Authors \\ Institutions \\ 1 Division of Gastroenterology and Hepatology, \\ Metrohealth Medical Center, Case Western Reserve \\ University, Cleveland, Ohio, United States \\ 2 Department of Internal Medicine, Metrohealth Medical \\ Center, Case Western Reserve University, Cleveland, \\ Ohio, United States \\ 3 Division of Gastroenterology, Hepatology and Nutrition, \\ Digestive Diseases and Surgery Institute, Cleveland \\ Clinic, Cleveland, Ohio, United States
}

Abdulfatah Issak ${ }^{1,2}$, Abbinaya Elangovan ${ }^{1,2}$, Roy D. Ferguson ${ }^{1,2}$, Nisheet Waghray ${ }^{1,2}$, Dalbir S. Sandhu ${ }^{3}$

submitted 24.9.2020

accepted after revision 23.2.2021

\author{
Bibliography \\ Endosc Int Open 2021; 09: E979-E985 \\ DOI 10.1055/a-1460-7776 \\ ISSN 2364-3722 \\ (C) 2021. The Author(s).
}

This is an open access article published by Thieme under the terms of the Creative Commons Attribution-NonDerivative-NonCommercial License, permitting copying and reproduction so long as the original work is given appropriate credit. Contents may not be used for commercial purposes, or adapted, remixed, transformed or built upon. (https://creativecommons.org/licenses/by-nc-nd/4.0/)

Georg Thieme Verlag KG, Rüdigerstraße 14,

70469 Stuttgart, Germany

Corresponding author

Dalbir S. Sandhu, MD, Director of Endoscopy, Digestive

Disease and Surgery Institute, Cleveland Clinic Akron General,

1 Akron General Avenue, Akron, $\mathrm{OH} 44307$, United States of

America

Fax: +1- 330-753-3465

drdalbir@gmail.com

\section{ABSTRACT}

Background and study aims Incidence of Post-ERCP pancreatitis (PEP) ranges from $1 \%$ to $10 \%$ in unselected patients and as high as $25 \%$ to $30 \%$ in high-risk patients. Rectal indomethacin administered before or immediately after an ERCP and prophylactic pancreatic duct stent placement (PPS) are associated with a reduction in the incidence of PEP. We sought to investigate the utilization rate for prophylactic rectal indomethacin and PPS in average and highrisk patients undergoing ERCP between 2014 and 2019.

Patients and methods We performed a retrospective analysis in the IBM Explorys database, a pooled, national deidentified clinical database of over 72 million unique patients from 26 health care networks and 300 hospitals across the United States from 2014 to 2019. Average and high-risk patients undergoing ERCP were identified using Systematized Nomenclature of Medicine Clinical Terms (SNOMED CT) diagnosis codes. PEP was defined by the presence of SNOMED CT diagnosis of acute pancreatitis and an inpatient admission within 5 days of an ERCP procedure.

Results Out of 31,050 adults who had undergone ERCP from 2014 to 2019 , only 10,500 individuals (33.8\%) had a PEP prophylaxis. Rectal indomethacin and PPS accounted for $82.4 \%$ and $12.9 \%$ respectively. Individuals with three risk factors had the highest PEP rates followed by individuals with two risk factors.

Conclusions Only one-third of all patients undergoing ERCP received prophylaxis in the form of rectal indothemacin and/or PPS in this large population-based data. Increased implementation of prophylactic use is needed in patients undergoing ERCP as supported by current guidelines.

\section{Introduction}

Endoscopic retrograde cholangiopancreatography (ERCP) is an invasive procedure employed as a diagnostic and therapeutic modality in patients with biliary and pancreatic disorders. Over 350,000 to 500,000 ERCPs are performed annually in the United States [1,2]. Post-ERCP pancreatitis (PEP) is one of the most frequent and feared complications of ERCP with a reported incidence ranging from $1 \%$ to $10 \%$ in unselected patients and as high as $25 \%$ to $30 \%$ in high-risk patients [3,4]. Identified high-risk features include patient related risk factors such as suspected sphincter of Oddi dysfunction (SOD), female sex, younger patient age ( $<40$ years), procedure-related risk factors such as pancreatic duct injection, sphincterotomy, and opera- 
tor-related factors such as lack of training [5-8]. While approximately $90 \%$ of cases are mild to moderate in severity, around $10 \%$ of cases are regarded as severe and account for most morbidity and rarely mortality in about $1 \%$ of patients [7, 9]. The direct and indirect healthcare costs of PEP exceed over \$150 million annually in the United States[10]. Given this clinical and economic burden, research about PEP prophylaxis has garnered great interest. Prophylactic pancreatic duct stents (PPSs) and rectal nonsteroidal anti-inflammatory drugs (NSAIDs) are the most rigorously studied mechanical and pharmacological interventions, respectively, for the prevention of PEP.

PPS placement in high-risk patients is regarded as the most effective mechanical prophylactic approach to reduce the incidence and severity of PEP [11-14]. In a pooled meta-analysis of prospective randomized controlled trials, no PPS placement was associated with a 3-fold increased risk of developing PEP [12]. Rectal NSAIDs (indomethacin or diclofenac) administered before or immediately after an ERCP are associated with a $35 \%$ to $65 \%$ reduction in the incidence of PEP $[4,15-17]$. The administration of rectal NSAIDs and PPS to reduce the incidence and severity PEP is further supported by multiple societal guidelines. The American Society of Gastrointestinal Endoscopy (ASGE) recommends rectal NSAID use to reduce incidence and severity of PEP in high-risk patients undergoing ERCP and suggests rectal indomethacin may decrease incidence and severity in average-risk patients [8]. Both the European Society of Gastrointestinal Endoscopy (ESGE) guideline published in 2014 and Japanese guidelines for the management of acute pancreatitis (AP) published in 2015 recommend prophylactic administration of rectal NSAIDs in all patients undergoing ERCP with no contraindication or pancreatic duct stent placement in highrisk patients $[7,18]$.

Despite overall evidence in the literature supporting the efficacy of prophylactic rectal NSAIDs and PPS in preventing PEP, advanced endoscopists seldom use rectal NSAIDs or PPS for patients undergoing $\operatorname{ERCP}[5,19]$. Besides small survey-based studies showing poor utilization of prophylactic rectal NSAIDs and PPS, no large database studies have looked at the utilization of rectal NSAIDs in average- and high-risk patients undergoing ERCP. Therefore, we sought to analyze the utilization of prophylactic rectal indomethacin and PPS in reducing incidence and severity of PEP in patients undergoing ERCP using a large publicly available, all-payer, nationally representative database in the United States.

\section{Patients and methods \\ Database/study design}

This was a retrospective analysis in the IBM Explorys database, a pooled, de-identified clinical database of over 72 million unique patients from 26 health care networks and 300 hospitals across the United States [20]. Explorys works behind the firewall of each participating institution and maps data using standard ontologies [21]. The data are de-identified to fit to restrictions of the Health Insurance Portability and Accountability Act (HIPAA) and Health Information Technology for Economic and Clinical Health (HITECH) acts. Explorys has various categories of data including demographics, history, exam finding, laboratory data, drug classes, diagnoses codes and billing information [20]. The ICD codes entered by the providers are mapped into Systematized Nomenclature of Medicine Clinical Terms (SNOMED CT) diagnosis codes. SNOMED CT is biomedical terminology that is about 40 times larger than International Classification of Disease (ICD) 9 and is hypothesized to have more clinical concepts per clinical document [22]. Similarly, the procedures are mapped using Current Procedural Terminology (CPT) codes. The data obtained through Explorys does not include any protected health information and does not require approval from institutional board.

\section{Participant selection}

Individuals aged $\geq 18$ years who underwent at least one ERCP procedure in the last 5 years were reviewed. We chose the last 5 years as literature supporting prophylactic use of rectal indomethacin has been more robust. Individuals with chronic kidney disease, peptic ulcer disease, or non-steroidal anti-inflammatory drug allergy were excluded. Subjects were considered high-risk if they were women, underwent ERCP at age $<40$ years, had SOD, pancreatic sphincterotomy, or a history of AP at least 30 days before ERCP. The subjects were risk-stratified as follows: 1) average-risk, absence of any of the studied risk factors; 2) individuals with one risk factor; 3 ) those with two risk factors; and 4) those with three risk factors. Prophylaxis for post-ERCP pancreatitis was studied in three categories: 1) rectal NSAIDs within 24 hours of ERCP without any endoscopic insertion of stent into pancreatic duct (CPT code: 43268); 2) endoscopic insertion of stent into pancreatic duct without receiving periprocedural rectal NSAIDs; and 3) rectal NSAID and endoscopic insertion of stent into pancreatic duct. PEP was defined by the presence of SNOMED CT diagnosis of AP and an inpatient admission within 5 days of an ERCP procedure.

\section{Statistical analysis}

Data were analyzed using univariate chi-square test. The primary outcome of the study was to evaluate the utilization of PEP prophylaxes in different risk groups. The secondary outcome was to compare the PEP rates in different risk groups. The PEP rate was calculated by dividing the number of individuals with PEP by the total number of individuals who underwent at least one ERCP during the study period in every risk group. The demographic details for individuals, including age at the time of procedure, sex, ethnicity, race, and insurance status, were compared between the subgroups. Calculations were performed using Microsoft Excel 2016. $P<0.05$ was considered statistically significant.

\section{Results}

Among 72 million unique patients active in the database, 31,050 adults who had undergone at least one ERCP in the last 5 years were included in the study. About $82 \%(25,590)$ had at least one of the studied risk factors of PEP. The most common high-risk condition in the studied population was female sex $(18,630 ; 60 \%)$ ( Fig. 1 ). 


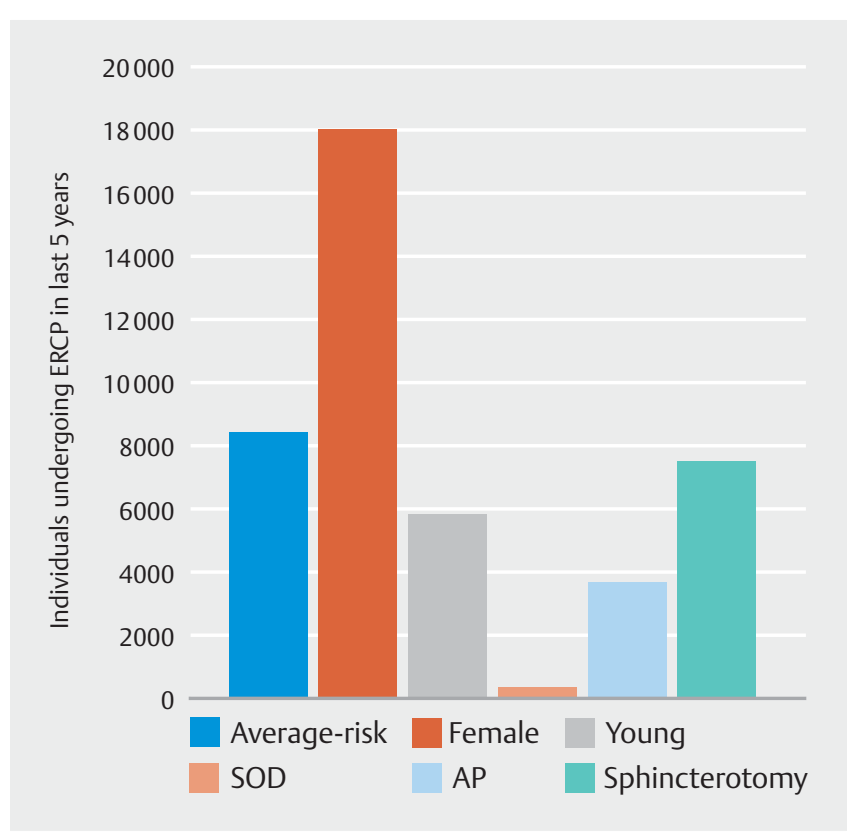

- Fig. 1 Baseline characteristics of the study population.

\section{Utilization of prophylaxis for post-ERCP pancreatitis}

Among those who underwent ERCP, 10,500 individuals (33.8\%) had a PEP prophylaxis (17\% average-risk, $83 \%$ high risk). Rectal NSAIDs was used for prophylaxis in 8,650 adults (17.2\% average-risk, $82.8 \%$ high risk). Rectal indomethacin accounted for all of the cases of rectal NSAID use. Endoscopic insertion of a stent in the pancreatic duct (PPS) for prophylaxis was used in 1,350 individuals (26.7\% average risk, $73.3 \%$ high-risk). Both rectal indomethacin and PPS were used in 500 individuals (8\% average risk, $92 \%$ high-risk). In the last group, $44 \%$ of the 500 individuals had two or more risk factors. In the overall subjects who underwent ERCP, there was a trend towards a higher proportion of high-risk individuals on rectal indomethacin compared to average-risk individuals ( $28 \%$ vs $27.3 \%, P=0.295$ ). However, there were significantly fewer average-risk individuals who received the combination prophylaxis of rectal indomethacin and PPS than high-risk individuals ( $0.7 \%$ vs $1.8 \%, P<0.0001)$ and surprisingly a higher proportion of average-risk adults received PPS (without rectal indomethacin) compared to highrisk individuals $(6.6 \%$ vs $3.9 \%, P<0.0001)$ ( $>$ Table 1 ).

The demographic details of the subgroups are listed in - Table 2. Young individuals (<40 years) had significantly higher rectal indomethacin use $(32.1 \%$ vs $26.8 \%, P<0.0001)$ than the older individuals but lower endoscopic pancreatic stent placement than older individuals $(2.6 \%$ vs $4.8 \%, P<0.0001)$. Women had higher rectal indomethacin use compared to men (29.2\% vs $25.8 \%, P<0.0001)$ but lower stent placement $(4.6 \%$ vs $5.2 \%, P=0.016)$ than men.

\section{Post-ERCP pancreatitis rates}

The prevalence of PEP in the unselected study population was $6.1 \%$. The PEP rate in the high-risk population was higher than the average-risk population $(6.4 \%$ vs $4.6 \%, P<0.0001)$ ( $\triangleright$ Ta- ble 3). Individuals with three risk factors had the highest PEP rates: female sex + youth +SOD: $20 \%$; female sex + AP+sphincterotomy: $11.8 \%$, followed by individuals with two risk factors: female sex+SOD: $11.1 \%$ and youth + sphincterotomy: $10.7 \%$ ( Table 3).

\section{Discussion}

This study used a large database with over 72 million unique patients and includes analyses of over 31,000 adults who underwent ERCP in the last 5 years. To date, limited data exist on the real-world use of prophylactic NSAIDs and/or PPS in average and high-risk patients undergoing ERCP. Smith et. al. recently published a paper that investigated the trend of indomethacin use and pancreatic duct stent placement for post-ERCP prophylaxis in a high-risk cohort from 2009 to 2018 [23]. In their analyses, Smith et. al. focused only on high-risk subjects with SOD or spasm and those who underwent pancreatic sphincterotomy and reported that use of prophylactic indomethacin and pancreatic duct stent placement lags behind current societal guidelines. While this exciting paper provides a report regarding prophylactic indomethacin use and/or pancreatic duct stent placement in high-risk cohorts, it lacks report on average-risk subjects and those who carry risk factors for PEP other than SOD or pancreatic sphincterotomy. This is one of the areas where our study differs. First, our study investigated both average and high-risk cohorts. Second, in the high-risk cohorts, we analyzed subjects with multiple high-risk features, including sex, gender, history of AP, history of SOD, and subjects who underwent pancreatic sphincterotomy. Third, we further risk-stratified subjects into three categories: those with one, two, or three risk factors and analyzed the incidence of PEP in each group. Analysis of indomethacin use in average-risk patients is very important as current societal guidelines recommend [7] or suggest [8] rectal indomethacin administration to reduce the risk and severity of PEP in average-risk individuals undergoing ERCP. An updated report on the practice patterns of prophylactic utilization in the form of rectal indomethacin or PPS placement assumes a greater significance as major guidelines including ASGE, ESGE and Japanese guidelines now recommend prophylaxis for PEP in all patients undergoing ERCP $[7,8,18]$. These guidelines are further supported by increasing literature showing that prophylactic rectal NSAIDs and PPS reduce the incidence and severity of PEP $[4,11-17,24]$.

Our study demonstrated that the two most effective PEP prophylaxes, i.e., rectal NSAIDs and PPS, are underutilized in patients undergoing ERCP in the US. Only about a third (27.9\%) of patients received rectal indomethacin for PEP prophylaxis while a smaller number (4.3\%) of patients had PPS and even a lower number (1.6\%) had both prophylactic rectal indomethacin and PPS. All cases of rectal NSAIDs were accounted for by indomethacin. This is plausible as literature supporting the prophylactic efficacy of indomethacin is more robust compared to rectal diclofenac $[8,16,17,25-27]$. The mounting evidence in the literature supporting efficacy of indomethacin over diclofenac appears to have permeated into the practice patterns of advanced endoscopists performing ERCP. Younger individuals 
Table 1 Utilization of Post-ERCP pancreatitis prophylaxis in average- and high-risk populations.

\begin{tabular}{|c|c|c|c|c|c|c|}
\hline \multirow[t]{3}{*}{ PEP prophylaxes } & \multirow[t]{2}{*}{ Average-risk } & \multicolumn{4}{|c|}{ High-risk $(\mathrm{N}=25,590)$} & \multirow{2}{*}{$\begin{array}{l}\text { Average-risk } \\
\text { vs any high- } \\
\text { risk } P \text { value }\end{array}$} \\
\hline & & Any high-risk & SOD dysfunction & Acute pancreatitis & Sphincterotomy & \\
\hline & $(N=5,460)$ & $(N=25,590)$ & $(N=350)$ & $(N=4,190)$ & $(N=8,300)$ & \\
\hline No prophylaxis & $3670(67.2 \%)$ & $16,880(66.0 \%)$ & $190(54.3 \%)$ & $2440(58.2 \%)$ & $6050(72.9 \%)$ & 0.089 \\
\hline Rectal NSAID & $1490(27.3 \%)$ & $7,160(28.0 \%)$ & $120(34.3 \%)$ & $1230(29.4 \%)$ & $1,810(21.8 \%)$ & 0.295 \\
\hline PPS & $360(6.6 \%)$ & $990(3.9 \%)$ & $20(5.7 \%)$ & $330(7.9 \%)$ & $280(3.4 \%)$ & $<0.0001$ \\
\hline Rectal NSAID + PPS & $40(0.7 \%)$ & $460(1.8 \%)$ & $20(5.7 \%)$ & $190(4.5 \%)$ & $160(1.9 \%)$ & $<0.0001$ \\
\hline
\end{tabular}

ERCP, endoscopic retrograde cholangiopancreatography; NSAID, nonsteroidal anti-inflammatory drug; PEP, post-ERCP pancreatitis; PPS, pancreatic duct stent.

- Table 2 Demographics of individuals with post-ERCP pancreatitis prophylaxis.

\begin{tabular}{|c|c|c|c|c|c|c|c|c|}
\hline \multicolumn{2}{|l|}{ Variables } & \multirow{2}{*}{$\begin{array}{l}\text { Individuals with ERCP } \\
(\mathbf{N}=\mathbf{3 1 , 0 5 0 )} \\
6,050\end{array}$} & \multicolumn{2}{|c|}{$\begin{array}{l}\text { Rectal NSAIDs } \\
(\mathrm{N}=8,650)\end{array}$} & \multicolumn{2}{|c|}{$\begin{array}{l}\text { PPS } \\
(N=1,350)\end{array}$} & \multicolumn{2}{|c|}{$\begin{array}{l}\text { PPS + Rectal NSAIDs } \\
(\mathrm{N}=500)\end{array}$} \\
\hline \multirow[t]{2}{*}{ Age } & $<40$ years & & 1,940 & $32.1 \%$ & 150 & $2.5 \%$ & 80 & $1.3 \%$ \\
\hline & $\geq 40$ years & 25,000 & 6,710 & $26.8 \%$ & 1,200 & $4.8 \%$ & 420 & $1.7 \%$ \\
\hline \multirow[t]{2}{*}{ Sex } & Male & 12,420 & 3,210 & $25.8 \%$ & 600 & $4.8 \%$ & 190 & $1.5 \%$ \\
\hline & Female & 18,630 & 5,440 & $29.2 \%$ & 750 & $4.0 \%$ & 310 & $1.7 \%$ \\
\hline \multirow[t]{2}{*}{ Ethnicity } & Non-Hispanic & 23,630 & 6,650 & $28.1 \%$ & 1,440 & $6.1 \%$ & 460 & $1.9 \%$ \\
\hline & Hispanic & 2,380 & 560 & $23.5 \%$ & 90 & $3.8 \%$ & 40 & $1.7 \%$ \\
\hline \multirow[t]{2}{*}{ Race } & Caucasian & 27,970 & 7,740 & $27.7 \%$ & 1,180 & $4.2 \%$ & 410 & $1.5 \%$ \\
\hline & African-American & 3,080 & 910 & $29.5 \%$ & 170 & $5.5 \%$ & 60 & $1.9 \%$ \\
\hline \multirow[t]{4}{*}{ Insurance } & Medicare & 9,540 & 2,110 & $22.1 \%$ & 610 & $6.4 \%$ & 180 & $1.9 \%$ \\
\hline & Medicaid & 3,450 & 990 & $28.7 \%$ & 90 & $2.6 \%$ & 70 & $2.0 \%$ \\
\hline & Private & 16,630 & 5,350 & $32.2 \%$ & 600 & $3.6 \%$ & 230 & $1.4 \%$ \\
\hline & Self-pay & 1,430 & 200 & $14.0 \%$ & 50 & $3.5 \%$ & 20 & $1.4 \%$ \\
\hline
\end{tabular}

ERCP, endoscopic retrograde cholangiopancreatography; NSAID non-steroidal anti-inflammatory drug; PEP, post-ERCP pancreatitis; PPS, pancreatic duct stent.

( $<40$ years) had a significantly higher rectal indomethacin use (32.1\% vs $26.8 \%, P<0.0001)$ but lower PPS placement than older individuals $(2.6 \%$ vs $4.8 \%, P<0.0001)$. This difference might be accounted for by more complex procedures perhaps in older, sicker patients. Our study points out a sex difference among men and women regarding the type of prophylactic intervention used. Women were more likely to receive rectal indomethacin $(29.2 \%$ vs $25.8 \%, P<0.0001)$ but a lower prophylactic stent ( $4.6 \%$ vs $5.2 \%, P=0.016)$ compared to men. This appears to be a novel finding in this study as there is a scarcity of literature citing similar findings. Our finding is consistent with a recent survey-based studies showing low numbers of prophylactic utilization in patients undergoing ERCP. A survey of US-based endoscopists $(\mathrm{N}=62)$ performing ERCP showed only $40 \%$ of endoscopists reported using prophylactic rectal NSAIDs in average-risk patients while $59.7 \%$ reported using in high-risk patients [5]. A United Kingdom-wide survey showed only $34.6 \%$ of endoscopists ( $\mathrm{N}=72$ ) used prophylactic NSAIDs while $52.5 \%$ $(\mathrm{N}=115)$ used prophylactic pancreatic stent [19]. Our study provides direct evidence that all patients undergoing ERCP are not receiving appropriate prophylactic interventions as recommended by the current guidelines $[7,8,18]$. Some of the reasons cited in the literature for poor utilization of pharmacological and mechanical prophylaxis include lack of awareness, lack of conviction of their benefits, cost, accessibility, and insufficient experience in inserting PPS [5, 19].

This study was not specifically designed to study the prevalence of PEP in this cohort due to difficulty in accurately diagnosing PEP and recording respective SNOMED CT codes into the database. According to ASGE guidelines, the accurate diagnosis of PEP requires a combination of clinical evidence such as abdominal/epigastric pain with supporting laboratory and/or imaging study and prolonged duration of hospital stay. Given that many patients report abdominal/epigastric discomfort post-ERCP and generally receive aggressive intravenous fluids, it is plausible to suspect that only moderate to severe cases of PEP are investigated and adequately diagnosed. Nonetheless, the overall prevalence of PEP in unselected patients in our study 
- Table 3 Risk-based post-ERCP pancreatitis rates.

\begin{tabular}{|c|c|c|c|c|c|c|c|c|c|c|}
\hline $\begin{array}{l}\text { No. risk } \\
\text { factors }\end{array}$ & Female & Young & SOD & AP & $\begin{array}{l}\text { Sphincter- } \\
\text { otomy }\end{array}$ & ERCP & PEP & $\begin{array}{l}\text { Rectal } \\
\text { NSAID }\end{array}$ & PPS & $\begin{array}{l}\text { Rectal NSAID + } \\
\text { PPS }\end{array}$ \\
\hline \multicolumn{11}{|c|}{ Average risk } \\
\hline 0 & No & No & No & No & No & 5,460 & $4.6 \%$ & $27.3 \%$ & $6.6 \%$ & $0.70 \%$ \\
\hline \multicolumn{11}{|l|}{ High-risk } \\
\hline Any & & & & & & 25,590 & $6.4 \%$ & $28.0 \%$ & $3.9 \%$ & $1.8 \%$ \\
\hline \multirow[t]{4}{*}{1} & Yes & No & No & No & No & 10,340 & $4.70 \%$ & $29.30 \%$ & $4.60 \%$ & $1.40 \%$ \\
\hline & No & Yes & No & No & No & 920 & $6.50 \%$ & $31.50 \%$ & $1.10 \%$ & $1.10 \%$ \\
\hline & No & No & No & Yes & No & 1,280 & $8.60 \%$ & $28.90 \%$ & $7.80 \%$ & $3.90 \%$ \\
\hline & No & No & No & No & Yes & 2,290 & $7.00 \%$ & $21.40 \%$ & $2.20 \%$ & $1.70 \%$ \\
\hline \multirow[t]{7}{*}{2} & Yes & Yes & No & No & No & 2,990 & $5.00 \%$ & $35.10 \%$ & $1.70 \%$ & $1.70 \%$ \\
\hline & Yes & No & Yes & No & No & 90 & $11.10 \%$ & $44.40 \%$ & $\mathrm{n} / \mathrm{a}$ & $11.10 \%$ \\
\hline & Yes & No & No & Yes & No & 1,200 & $8.30 \%$ & $32.50 \%$ & $6.70 \%$ & $3.30 \%$ \\
\hline & Yes & No & No & No & Yes & 3,240 & $8.00 \%$ & $22.20 \%$ & $3.40 \%$ & $1.20 \%$ \\
\hline & No & Yes & No & Yes & No & 210 & $4.80 \%$ & $33.30 \%$ & $4.80 \%$ & $4.80 \%$ \\
\hline & No & Yes & No & No & Yes & 280 & $10.70 \%$ & $17.90 \%$ & $3.60 \%$ & $\mathrm{n} / \mathrm{a}$ \\
\hline & No & No & No & Yes & Yes & 420 & $9.50 \%$ & $19.00 \%$ & $0.00 \%$ & $7.10 \%$ \\
\hline \multirow[t]{8}{*}{3} & Yes & Yes & Yes & No & No & 50 & $20.00 \%$ & $60.00 \%$ & $\mathrm{n} / \mathrm{a}$ & $\mathrm{n} / \mathrm{a}$ \\
\hline & Yes & Yes & No & Yes & No & 290 & $10.30 \%$ & $37.90 \%$ & $6.90 \%$ & $\mathrm{n} / \mathrm{a}$ \\
\hline & Yes & Yes & No & No & Yes & 1,190 & $9.20 \%$ & $25.20 \%$ & $1.70 \%$ & $0.80 \%$ \\
\hline & Yes & No & No & Yes & Yes & 510 & $11.80 \%$ & $25.50 \%$ & $9.80 \%$ & $5.90 \%$ \\
\hline & Yes & No & Yes & Yes & No & 30 & $\mathrm{n} / \mathrm{a}$ & $\mathrm{n} / \mathrm{a}$ & $\mathrm{n} / \mathrm{a}$ & $\mathrm{n} / \mathrm{a}$ \\
\hline & Yes & No & Yes & No & Yes & 90 & $\mathrm{n} / \mathrm{a}$ & $\mathrm{n} / \mathrm{a}$ & $\mathrm{n} / \mathrm{a}$ & $\mathrm{n} / \mathrm{a}$ \\
\hline & Yes & No & Yes & Yes & No & 30 & $\mathrm{n} / \mathrm{a}$ & $\mathrm{n} / \mathrm{a}$ & $\mathrm{n} / \mathrm{a}$ & $\mathrm{n} / \mathrm{a}$ \\
\hline & No & Yes & No & Yes & Yes & 40 & $\mathrm{n} / \mathrm{a}$ & $25.00 \%$ & $\mathrm{n} / \mathrm{a}$ & $\mathrm{n} / \mathrm{a}$ \\
\hline \multicolumn{11}{|c|}{$\begin{array}{l}\text { ERCP, endoscopic retrograde cholangiopancretography; PEP, post ERCP pancreatitis; AP acute pancreatitis; NSAID, nonsteroidal anti-inflammatory drug; SOD } \\
\text { sphincter of Oddi; PPS, pancreatic duct stent. } \\
\text { Individuals with the following risk factors were too low to report: SOD only, young-SOD, SOD-AP, SOD-sphincterotomy, young-SOD-AP, SOD-AP-sphincterotomy, } \\
\text { individuals with } 4 \text { or higher risk factors. }\end{array}$} \\
\hline
\end{tabular}

was $6.1 \%$ but was higher in high-risk patients (6.4\%), which is in line with prior studies that showed similar prevalence rates [3, $4,11]$. AP is the most common serious complication of ERCP with substantial morbidity and mortality. The frequency of PEP ranges from $1 \%$ to $10 \%$ and as high as $25 \%$ to $30 \%$ in high-risk patients $[3,4,11]$. Prophylactic PPS and rectal NSAIDs are the most effective mechanical and pharmacologic interventions for the prevention of PEP. In a prospective randomized controlled trial, Ali et. al showed that PPS placement is associated with a lower incidence of PEP ( $5 \%$ vs. $27 \%$; $P<0.05$ ) [11]. It is surmised that papillary trauma and manipulation during ERCP can lead to papillary edema and spasm of the sphincter of Oddi, which impacts the outflow of pancreatic juice. Thus, placement of pancreatic duct stent keeps the duct open and facilitates drainage of pancreatic juice which reduces subsequent acute pancreatic inflammation [11-14]. Several chemoprophy- lactic approaches (eg, allopurinol, nifedipine, octreotide, somatostatin, protease inhibitors, nitroglycerin, and corticosteroids) have been studied as prophylaxis for post-ERCP pancreatitis [28-31]; However, these studies yielded disappointing results. Only rectal NSAIDs have been shown to reduce the incidence and severity of PEP [4, 15-17].

While a majority of patients received rectal indomethacin for prophylaxis, a higher proportion of average risk patients received prophylaxis in the form of PPS. There are few plausible explanations for the higher proportion of PPS in average-risk patients without concomitant administration of rectal NSAIDs. First, many average-risk patients undergo ERCP in private/outpatient centers as opposed to tertiary care centers in which both high risk and average risk procedures are performed. Practically, pancreatic duct stents are kept in the endoscopy suite and can be readily accessible while indomethacin is generally stored in 
the pharmacy, at least in the hospital setting, and might require a prescription. Second, it is unclear if private/outpatient centers are equipped with an associated pharmacy that can supply indomethacin if needed. If not planned in advance, these factors might delay availability/administration of prophylactic rectal indomethacin compared to PPS placement. A small number of patients $(1.6 \%)$ received a combination of both rectal indomethacin and PPS in this study. While combination therapy is not the standard of care, there is literature showing that the combination of rectal NSAIDs and PPS can reduce the incidence of PEP. In a network meta-analysis, Akbar et. al. showed that rectal NSAIDs combined with PPS (OR, 0.41; $95 \% \mathrm{Cl}, 0.19-$ 0.87 ) reduced the risk of $P E P$ in average- and high-risk patients compared with placebo [32]. However, in the same study, researchers indicated that a combination of rectal NSAIDs and pancreatic duct stenting did not further reduce the risk of PEP compared to the use of rectal NSAIDs (OR, 1.46; $95 \% \mathrm{CI}, 0.79-$ 2.69) or stents (OR, $0.70 ; 95 \% \mathrm{Cl}, 0.40-1.20)$ alone [32]. In our analyses, $92 \%$ of the patients who received combination therapy had at least one high-risk feature and $44 \%$ carried two high-risk features. According to the current ASGE guidelines, there is insufficient evidence to support a combination of PPS and rectal NSAID for PEP prophylaxis [8].

In the overall study population, a higher number of patients received prophylactic rectal indomethacin compared to PPS. This can partially be attributed to the ease of administration of rectal indomethacin compared to PPS coupled with literature supporting the superiority of prophylactic rectal NSAIDs over PPS. In a network of meta-analysis, Akbar et. al. showed that rectal NSAIDs were superior to pancreatic duct stenting and were not inferior to the combination of rectal indomethacin and prophylactic pancreatic stent placement for the prevention of PEP [32]. Logistically, rectal NSAIDs are inexpensive, easily available, easier to administer and in some instances can preempt the need for repeat ERCP for stent removal. Moreover, there is the potential of failed pancreatic stent placement which can lead to severe complications $[7,9]$ in some patients. Such risk is non-existent in patients without contraindication who receive prophylactic rectal NSAIDs. Direct comparisons of rectal NSAIDs alone with PPS are lacking so far.

Our study supports prior literature showing the prophylactic benefit of rectal indomethacin and PPS in patients undergoing ERCP and further demonstrates in a nationally representative data that only one-third of all patients undergoing ERCP are receiving such prophylaxis. It is also noteworthy that in the current study, an overwhelming majority of patients undergoing ERCP can be characterized as high-risk given that $83 \%$ of the study population had at least one high-risk feature. This observation is important as it is well known and also evident in this study that a higher number of risk factors increase the risk of PEP synergistically and provides further support for prophylaxis in this patient population. As evident in $>$ Table 3 , young female patients with SOD accounted for the highest rate of PEP compared to a combination of other risk factors. In our analyses, a combination of female sex with any of the studied risk factors such as SOD (a condition that occurs primarily in women), sphincterotomy, or history of AP were strongly associated with an increased incidence of PEP. This finding is consistent with prior studies showing that women, in general, are at a higher risk for PEP regardless of clinical context or technical difficulty of ERCP and might develop a severe form of PEP [33]. Similar to prior studies, history of SOD and undergoing sphincterotomy accounted for a higher incidence of PEP among the risk factors studied with the exception of female sex [34, 35].

Our study has some limitations inherent to administrative database analysis research. First, this study relies on SNOMED CT diagnosis codes for establishing diagnoses. Theoretically, under/miscoding can lead to misclassification bias. Second, the consensus definition and classification of PEP includes clinical symptoms suggestive of AP such as abdominal pain, amylase $>3$ times normal limit 24 hours after the procedure, and prolonged hospital stay of 2 to 3 days [8]. Prolonged length of stay which is one of the criteria for PEP diagnosis is a variable that cannot be evaluated using this database. Due to this limitation, we restricted our search to a documented diagnosis code of PEP. We recognize this to be a limitation as some of the patients could develop signs and symptoms of AP and could fit the criteria for PEP, however, will not have the corresponding correct diagnosis charted. This might underestimate the overall prevalence of PEP especially in this high-risk patient population and because of that our study was not designed to specifically study the prevalence of PEP in this cohort.

Potential mechanism of PEP are multifactorial and includes patient, procedure or endoscopist related factors. Patientrelated risk factors such as a history of PEP (OR: 5.35), SOD (OR 2.60), female gender (OR 2.51) and procedure-related risk factors such as moderate to difficulty cannulation (6 to 15 attempts) (OR: 3.41), Sphincterotomy (OR 3.07), > 1 pancreatic duct contrast injection (OR 2.72) are all significant predictors of PEP. Similarly, a multicenter prospective study that compared low (<200 ERCPs/year) and large (>200 ERCPs/year) volume centers showed that large-volume centers had fewer overall complications ( $2.0 \%$ vs. $7.1 \%, P<0.001)$, fewer complicationrelated deaths $(0.18 \%$ vs. $0.75 \%, P<0.05)$ and a significantly increased risk of pancreatitis in low-volume centers (RR 2.8) [36]. The use of a population-level database study limited us from including some of these relevant risk factors including index procedure, the interval between procedures, numbers of cannulation attempts, difficult cannulation, low- vs large-volume centers, and expertise of the endoscopist. Nevertheless, the large size of the database and a comprehensive mixture of the patient populations are valuable strengths of the study.

\section{Conclusions}

In summary, we demonstrated in this large database study that only one-third of all patients undergoing ERCP received prophylaxis in the form of rectal indomethacin and PPS. In an effort to significantly reduce the incidence, severity, and economic and social burden of PEP, widespread use of prophylactic rectal indomethacin and, if appropriate, PPS placement should be considered in all patients undergoing ERCP without contraindications for PEP prophylaxis. 


\section{Competing interests}

The authors declare that they have no conflict of interest.

\section{References}

[1] Cotton PB. Are low-volume ERCPists a problem in the United States? A plea to examine and improve ERCP practice-NOW Gastrointest Endosc 2011; 74: 161-166

[2] Peery AF, Crockett SD, Murphy CC et al. Burden and cost of gastrointestinal, liver, and pancreatic diseases in the united states: update 2018. [published correction appears in Gastroenterology 2019; 156 : 1936] Gastroenterology 2019; 156: 254-272.e11

[3] Andriulli A, Loperfido S, Napolitano G et al. Incidence rates of postERCP complications: a systematic survey of prospective studies. Am J Gastroenterol 2007; 102: 1781-1788

[4] Yaghoobi M, Alzahrani MA, McNabb-Baltar J et al. Rectal indomethacin prevents moderate to severe post-ERCP pancreatitis and death and should be used before the procedure: a meta-analysis of aggregate subgroup data. J Can Assoc Gastroenterol 2018; 1: 67-75

[5] Avila P, Holmes I, Kouanda A et al. Practice patterns of post-ERCP pancreatitis prophylaxis techniques in the United States: a survey of advanced endoscopists. Gastrointest Endosc 2020; 91: 568-573.e2

[6] Testoni PA, Mariani A, Giussani A et al. Risk factors for post-ERCP pancreatitis in high- and low-volume centers and among expert and non-expert operators: a prospective multicenter study. Am J Gastroenterol 2010; 105: 1753-1761

[7] Dumonceau JM, Andriulli A, Elmunzer B] et al. Prophylaxis of postERCP pancreatitis: European Society of Gastrointestinal Endoscopy (ESGE) Guideline - updated June 2014. Endoscopy 2014; 46: 799-815

[8] ASGE Standards of Practice Committee. Chandrasekhara V, Khashab MA et al. Adverse events associated with ERCP. Gastrointest EndosC 2017; 85: 32-47

[9] Testoni PA. Preventing post-ERCP pancreatitis: where are we? JOP 2003; 4: 22-32

[10] Kochar B, Akshintala VS, Afghani E et al. Incidence, severity, and mortality of post-ERCP pancreatitis: a systematic review by using randomized, controlled trials. Gastrointest Endosc 2015; 81: 143149.e9

[11] Fazel A, Quadri A, Catalano MF et al. Does a pancreatic duct stent prevent post-ERCP pancreatitis? A prospective randomized study. Gastrointest Endosc 2003; 57: 291-294

[12] Singh P, Das A, Isenberg G et al. Does prophylactic pancreatic stent placement reduce the risk of post-ERCP acute pancreatitis? A metaanalysis of controlled trials Gastrointest Endosc 2004; 60: 544-550

[13] Tarnasky PR. Mechanical prevention of post-ERCP pancreatitis by pancreatic stents: results, techniques, and indications. JOP 2003; 4: $58-67$

[14] Phillip V, Pukitis A, Epstein A et al. Pancreatic stenting to prevent post-ERCP pancreatitis: a randomized multicenter trial. Endosc Int Open 2019; 7: E860-E868

[15] Elmunzer B], Waljee AK, Elta GH et al. A meta-analysis of rectal NSAIDs in the prevention of post-ERCP pancreatitis. Gut 2008; 57: 1262 1267

[16] He X, Zheng W, Ding Y et al. Rectal indomethacin is protective against pancreatitis after endoscopic retrograde cholangiopancreatography: systematic review and meta-analysis. Gastroenterol Res Pract 2018; 2018: 9784841

[17] Elmunzer B], Scheiman JM, Lehman GA et al. A randomized trial of rectal indomethacin to prevent post-ERCP pancreatitis. N Engl J Med 2012; 366: 1414-1422
[18] Yokoe M, Takada T, Mayumi T et al. Japanese guidelines for the management of acute pancreatitis: Japanese Guidelines 2015. J Hepatobiliary Pancreat Sci 2015; 22: 405-432

[19] Hanna MS, Portal AJ, Dhanda AD et al. UK wide survey on the prevention of post-ERCP pancreatitis. Frontline Gastroenterol 2014; 5: 103110

[20] IBM. The IBM Explorys Platform.https://www.ibm.com/downloads/ cas/4P0QB9JN

[21] Kaelber DC, Foster W, Gilder J et al. Patient characteristics associated with venous thromboembolic events: a cohort study using pooled electronic health record data. JAMIA 2012; 19: 965-972

[22] Nadkarni PM, Darer JA. Migrating existing clinical content from ICD-9 to SNOMED. JAMIA 2010; 17: 602-607

[23] Smith ZL, Elmunzer BJ, Cooper GS et al. Real-world practice patterns in the era of rectal indomethacin for prophylaxis against post-ERCP pancreatitis in a high-risk cohort. Am J Gastroenterol 2020; 115: $934-$ 940

[24] Barkin JA, Souto EO, Barkin JS et al. Rectal Indomethacin should be used routinely in all patients for the prevention of post-ERCP pancreatitis. Gastrointest Endosc 2017; 895: 687-688

[25] Inamdar S, Han D, Passi M et al. Rectal indomethacin is protective against post-ERCP pancreatitis in high-risk patients but not averagerisk patients: a systematic review and meta-analysis. Gastrointest Endosc 2017; 85: 67-75

[26] Del Olmo Martínez L, Velayos Jiménez B, Almaraz Gómez A. Rectal diclofenac does not prevent post-ERCP pancreatitis in consecutive highrisk and low-risk patients. Rev Esp Enferm Dig 2018; 110: 505-509

[27] Katoh T, Kawashima K, Fukuba N et al. Low-dose rectal diclofenac does not prevent post-ERCP pancreatitis in low- or high-risk patients. J Gastroenterol Hepatol 2020; 35: 1247-1253

[28] Andriulli A, Leandro G, Federici T et al. Prophylactic administration of somatostatin or gabexate does not prevent pancreatitis after ERCP: an updated meta-analysis. Gastrointest Endosc 2007; 65: 624-632

[29] Bhatia V, Ahuja V, Acharya SK et al. A randomized controlled trial of valdecoxib and glyceryl trinitrate for the prevention of post-ERCP pancreatitis. J Clin Gastroenterol 2011; 45: 170-176

[30] Shao LM, Chen QY, Chen MY et al. Nitroglycerin in the prevention of post-ERCP pancreatitis: a meta-analysis. Dig Dis Sci 2010; 55: 1-7

[31] Sherman S, Blaut U, Watkins JL et al. Does prophylactic administration of corticosteroid reduce the risk and severity of post-ERCP pancreatitis: a randomized, prospective, multicenter study. Gastrointest Endosc 2003; 58: 23-29

[32] Akbar A, Abu Dayyeh BK, Baron TH et al. Rectal nonsteroidal anti-inflammatory drugs are superior to pancreatic duct stents in preventing pancreatitis after endoscopic retrograde cholangiopancreatography: a network meta-analysis. Clin Gastroenterol Hepatol 2013; 11: 778-783

[33] Freeman ML, DiSario JA, Nelson DB et al. Risk factors for post-ERCP pancreatitis: a prospective, multicenter study. Gastrointest Endosc 2001; 54: 425-434

[34] Sherman S, Lehman GA. ERCP- and endoscopic sphincterotomy-induced pancreatitis. Pancreas 1991; 6: 350-367

[35] Tarnasky PR, Palesch YY, Cunningham JT et al. Pancreatic stenting prevents pancreatitis after biliary sphincterotomy in patients with sphincter of Oddi dysfunction. Gastroenterology 1998; 115: 15181524

[36] Loperfido S, Angelini G, Benedetti G et al. Major early complications from diagnostic and therapeutic ERCP: a prospective multicenter study. Gastrointest Endosc 1998; 48: 1-10 